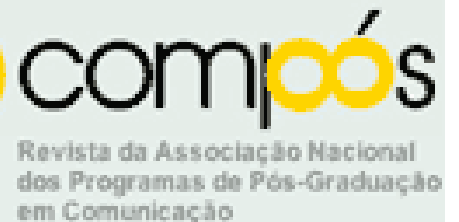

Este artigo foi publicado na edição 1, em dezembro de 2004, da revista eletrônica e-compós: http://www.compos.org.br/e-compos

\title{
CAMINHOS DA COMUNICAÇÃO CONTEMPORÂNEA
}

\author{
Gottfried Stockinger ${ }^{1}$
}

UFPa

\section{Introdução -}

\section{Experiência estética, comunicação e sociedade}

Desde a modernidade, a experiência artística instaura a produção da arte pela arte. Cria-se um campo de comunicação autónomo em relação à experiência do mundo de vida cotidiano, parecido com o que ocorreu com outro sub-sistema da sociedade, a ciência. Muitas vezes transgredindo as normas herdadas da tradição, e rompendo com ela, justificando assim seu desenvolvimento. $\mathrm{Na}$ verdade, sabemos que se trata de uma pretensão do mundo da arte de querer autocriar-se, e ao mesmo tempo valer enquanto representação de formatos e estilos de vida, atribuindo-lhes valores estéticos.

No mundo da moda, da publicidade, do jornalismo, da web-art e de outras formas, a performance do produto tem se tornado um indicador não apenas de sucesso empresarial, mas também e sobremaneira da esteticização cada vez

\footnotetext{
${ }^{1} \mathrm{O}$ autor é PhD pela Universidade Viena, Áustria, sociólogo e teórico da comunicação, atualmente prof. visitante do Programa de Mestrado em Comunicação e Linguagens da Universidade Tuiuti do Paraná, Curitiba. Já trabalhou no Brasil como Professor da UFPa - Dep. Sociologia, e na UFBa - Facom - Programa de PósGraduação em Comunicação e cultura contemporâneas. Faz parte do grupo de pesquisa sistémica "Unified Theory of Information", na Universidade de Tecnologia, Viena. Autor de vários livros, o mais recente em português "A Sociedade da comunicação - o contributo de Niklas Luhmann".
} 
mais diferenciada e generalizada da experiência de vida. A diversificação dos gostos é um produto da mídia, mas serve, no próximo passo, como ambiente poderoso de uma seleção estética, muitas vezes em forma linguística e corporal. Opondo-se à visão de comunicação enquanto uma relação puramente técnica e mecânica entre emissores e receptores, e enfatizando a variedade contingente do sentido da mensagem, Gregory Bateson (1972) constata que a comunicação se compara a uma orquestra, e não a uma linha telegráfica. Pierre Levy (1996) usa uma imagem parecida, referindo-se à interação política via ciberespaço como sendo um "coral polifônico improvisado"2 Todas as imagens e linguagens são polissêmicas. Desta maneira se produzem significantes que geram uma "cadeia flutuante" de significados, dependendo dos filtros usados pelo receptor. Tal polissemia coloca em dúvida qualquer sentido emergente (Barthes, 1990). Quando um significante possui vários significados (polissemia), se abre a possibilidade do confronto das diferentes leituras realizadas, a partir de ambientes e contextos diferentes.

Há um processo de "troca” das diferentes formas de ler, dizer, fazer, compreender, aprender e ensinar que circulam entre os atores. É desta diferenciação que se constitui a singularidade de cada um deles. Assim, os sujeitos avançam na construção e apropriação de novos saberes a partir de uma comunicação em cadeia, ainda que contingente.

Como comungar e comunicar experiências artísticas, estéticas, linguísticas, numa época em que surgem, em polissonia, os mais variados dispositivos de difusão e interação, muitos deles passam a ser maquinais, digitais, globais, em rede?

Será que seu único sentido será o de acentuar a natureza efémera e fluida da experiência estética?

Será que dependerão apenas de um acontecimento qualquer, ligado a u m valor ou a um efeito estratégicos, que tem o seu fim na própria realização de um produto estético ou linguístico?

Para responder a estas perguntas há de estender o horizonte. Há de olhar para os novos campos de aplicação de princípios estéticos, comunicacionais, que penetraram nos mundos de vida. Na sociedade contemporânea, linguagens,

\footnotetext{
${ }^{2}$ Levy, 1996, p. 67
} 
códigos e suas tecnologias objetivam a constituição de competências e habilidades indispensáveis para a vida. Precisamos compreender e usar os sistemas simbólicos das diferentes linguagens, como meios de organização cognitiva da realidade pela constituição de significados, expressão, informação e comunicação.

Há de confrontar opiniões e pontos de vista sobre as diferentes formas e formatos de expressão e suas manifestações específicas. E há de levar em conta que os recursos expressivos de linguagens e formas de expressão nem sempre estão compatíveis com as condições de produção e recepção. Por exemplo, compreender e usar a língua portuguesa gera uma significação e integração diferentes, um mundo de identidade própria, que não ser repete quando se navega na rede, onde o inglês domina, via de regra. Na rede, todos somos estrangeiros. Mesmo os internautas de língua materna inglesa são logo reconhecidos como tais, e representam "estranhos" para os não nativos do idioma. Isso leva a necessidade de ampliar o conceito de linguagens, incluindo o de "língua estrangeira", como instrumento de acesso e interpretação de informações e de outras culturas e grupos sociais.

Daí se poderá depreender toda uma gama de investimentos que a sociedade precisa aplicar para a compreensão dos caminhos da comunicação, nomeadamente:

Entender os princípios das tecnologias da comunicação e da informação Associá-las aos conhecimentos científicos, às linguagens que lhes dão suporte e aos problemas que se propõem solucionar.

Entender a natureza das tecnologias da informação como integração de diferentes meios de comunicação, linguagens e códigos, bem como a função integradora que elas exercem na sua relação com as demais tecnologias.

Finalmente há de entender o impacto destas tecnologias na sua vida, nos processos de produção, no desenvolvimento do conhecimento e na vida social.

Estamos diante um desenvolvimento de um processo por vezes descrito como mítico-poiético, de formato contingente, ambivalente, sujeito à percepção de sujeitos. Esta converte a relação dos seres com o seu entorno num mundo próprio. É isso que faz com que a experiência estética possa ser descrita em termos de uma teoria social que se baseia na autopoiese de sistemas sociais e personais. 


\section{O caminho da autopoiese não-linear}

Se a raiz da palavra comunicar aponta originalmente para o significado de compartilhar algo, de estar ligado, de ter algo em comum, tal se modifica, à medida que o conceito se estende à produção artística. Interpretar signos, sinais, referências estéticas e de linguagem requer um olhar diferente do sentido dado à noção de comunicação, no cotidiano, onde é tido como uma "troca” de informação.

Fato é que foram sobretudo os avanços tecnológicos que fizeram a mass-mídia dar um salto, nos anos 1930, para depois aplicar tal mídia na batalha psicológica e de propaganda durante a segunda guerra mundial. A falta de interatividade do meio técnico limitou a mídia à mera difusão. Não é de se admirar, portanto, que os primeiros teoremas da comunicação social se voltam inicialmente para a compreensão da transmissão mecânica e linear de dados. Apenas nas ultimas décadas do sec. XX o teorema da comunicação incorporará os avanços das teorias sobre a percepção de sistemas cognitivos, biológicos, neuronais e psíquicos. Assim fortalecido, o teorema básico ultrapassa o até então dominante modelo técnico da comunicação enquanto transmissão de dados entre "emissor" e "receptor", pelo qual os efeitos da comunicação seguem o princípio mecânico de actio est reactio.

Mesmo em processos puramente técnicos, tal princípio não se aplica perfeitamente. Impurezas e "ruído" de vária ordem podem impedir o sucesso da transmissão. O modelo de emissor e receptor precisou ser aprimorado. Isso ocorreu nomeadamente com o desenvolvimento da telefonia e do telégrafo, impulsionado por dois engenheiros de rádio e telefonia, Shannon e Weaver, no final dos anos 40, quando trabalharam para a companhia telefónica Bell, nos EUA. A tarefa para os engenheiros consistia em encontrar uma modalidade de transmissão de dados por fio telefónico ("canal") que apresentasse o mínimo de ruído (noise) perturbador. Porque se o ruído ultrapassar um determinado limiar, a mensagem original fica incompreensível.

Ora, o controle deste limiar é praticamente impossível em situações sociais que apresentam novidades, porque elas vivem de "ruído". Ou seja, em ambientes 
de produção cultural e artística, onde a apresentação do novo é conditio sine qua non para qualquer sucesso, tal controle praticamente chega a inexistir. Ou, quando existe, é sempre questionado e tido como indesejável, como mostra o debate brasileiro sobre o estatuto do jornalismo, suscitado pelo governo.

Mesmo que o modelo clássico Emissor-Canal-Receptor se tenha revelado insuficiente e falho quando aplicado à interação de sistemas cognitivos, ele permite visualizar uma interface que "desvirtua" a mensagem. Ele trata a interface "canal" como um ambiente, um meio, uma "mídia", cuja atividade gera desvios e novas margens de interpretação da mensagem transmitido. A concepção do canal enquanto interface de comunicação revela a existência de um terceiro elemento que atua independente e de seu próprio modo; o que leva a explicação de comunicação como um processo autopoiético, com uma lógica própria de funcionamento, independente das intenções de emissores e receptores.

O que no modelo técnico é o canal, no modelo social passa a ser um meio mediatizador ("medium") com qualidades criativas (por exemplo a linguagem), onde qualquer "ruído no canal" está sujeito a interpretações pelo receptor, conforme seus condicionamentos e interesses. Mas ele também pode tentar não compreende-la, apesar dela chegar tecnicamente perfeita aos seus ouvidos.

A comunicação se torna contingente, porque os atores usam os sinais e linguagens num ambiente que se transforma em parte integrante do seu comunicado. Emissores e receptores se confundem, já que estão interligados em circuitos de retroalimentação. Tratando-se de sistemas psicossociais, já não existe uma relação linear de causa e efeito entre emissor e receptor. Causa e efeito da comunicação podem ser constatados apenas numa observação posterior do comportamento do emissor e do receptor. São eles que marcam o processo de comunicação conforme suas interpretações, próprias de cada um. Actio non est reactio.

Observando os mecanismos de realimentação (feedback) na comunicação, chega-se à compreensão dos elementos participantes (emissor, interface, receptor) como sendo sistemas "cognitivos" (no sentido lato quando aplicado à interface, ao canal, à mídia), que funcionam de forma autónoma e autopoiética dentro de circuitos reguladores. Eles expressam dados em gestos, códigos e linguagens próprios, de maneira operacionalmente fechada. Quando 
McLuhan (1964) escreveu seu clássico, quarenta anos atras, ele certamente não podia prever o grau de automação que a comunicação humana iria alcançar hoje em dia. O medium co-produz a mensagem e a informação aparece em determinados formatos, quer na vida cotidiana, quer na mass-mídia.

Visto assim, a comunicação contemporânea deixa de ser percebida como uma "troca de informações", quando se pressupõe sistemas cognitivos operacionalmente fechados que reagem a si próprios e criam assim o mundo de sua reflexão. A troca não acontece. O que há é a exibição de imagens, de gestos, de sinais, de falas, sujeitas a uma interpretação de livre arbítrio.

O problema sociológico que este fato implica é o seguinte: se não há troca de informação, mas "apenas" autopoiese de sistemas psíquicos em ambientes comunicativos incertos, o que significa então a compreensão aparente que sentimos diante uma obra de arte ou mesmo diante de uma obra científica? Niklas Luhmann (1987) mostra que, para surgir comunicação, e com ela u m sistema de sentido, de compreensão, não precisa existir uma cultura comum, prefixada. Há uma situação de contingência (de referência "vazia" e indeterminada) entre a obra e seu observador, tal qual a houve com o criador. Ela deixa liberdade de criação em ambos os lados, emissor e receptor. Tal contingência de sistemas autopoiéticos pode se tornar um impulso produtivo para a génese de um espaço comunicativo entre criador, observador, obra.

O mesmo ocorre na comunicação inter-humana: tomando uma situação que ponha duas pessoas estranhas frente a frente, podemos observar que qualquer gesto, qualquer palavra, e até qualquer silêncio, pode produzir comunicação e fazer, assim surgir um sistema social, ou seja um "relacionamento" capaz de se estabilizar.

A comunicação viva emerge, portanto, de instabilidades, de flutuações permanentes às quais ela tem de resistir, se quiser ganhar estabilidade. A estrutura emergente, por mais sólida e estável que possa parecer, "guarda", no entanto, a dupla contingência que se encontra no seu início, ou seja, sempre há espaço para dúvidas e interpretações.

Para explicar a aparente compreensão entre o autor, a obra, e o observador, e a formação conseqüente de um sistema social, a teoria de Luhmann incorpora, portanto, o acaso e o princípio de "order from noise" de uma teoria geral de sistemas. Ele penetra na genética dos processos de comunicação, ou seja, ele vê 
comunicação como fenômeno emergente. A observação pessoal se reconhece apenas num processo de comunicação que têm qualidades emergentes, em cada momento. Senão houvesse novidades, nada haveria a ser observado.

É por isso que a maioria dos fenómenos contemporâneos de comunicação explora os aspectos complexos e construtivistas da comunicação. Wittgenstein, no "Tractatus logico-filosoficus" já anotou este caráter construtivo, afirmando que o mundo é tudo o que acontece. Ele é o conjunto dos fatos construídos na comunicação humana, e não o conjunto de coisas. Ele é, segundo ele, um mundo comunicado, interpretado, e não preexistente. Ele é um mundo de signos e de seus significados. Ora, o espaço da arte contêm as mesmas conotações semiológicas. Não há uma validade geral dos signos e do seu uso; há, e há sim, diferenças entre os códigos e a sua articulação nas situações de comunicação. É só que há. É disso que vive a reprodução da cadeia incessante de interpretações subsequentes. No estudo dos signos linguísticos o aspecto pragmático, que explica o efeito da comunicação, ou seja a sua relação com a ação, é o mais difícil de entender. Porque se "Não é possível não comunicar" (ver Watzlawick, 1967), se tudo é comunicação, a própria interpretação passa a ser um processo incessante.

Estes e outros exemplos mostram, que a maioria das abordagens atuais da comunicação não têm como não dar ênfase aos aspectos emergentes e genéticos da comunicação. Superam, assim, a visão tradicional da comunicação sociológica, que a viu como transmissão de sentido de um sujeito para outro ou como troca entre eles.

\section{O caminho da evolução da complexidade estética}

Quando se focaliza o momento temporal e o entorno espacial no qual ruído passa a dar lugar a informação, não se pode tomar os comunicandos - autor, obra, observador - como subsistemas de um sistema cultural já preestabelecido. Um tal sistema, caso existir, não passa, por sua vez, de um produtor de ruído, a partir do qual surge a diferença entre sistema de sentido e ambiente de signos e sinais. Esta diferença é insuperável porque as combinações possíveis sempre excedem as combinações atualizadas, em cada momento. 
É por isso que sistemas de comunicação artística e estética evoluem e não podem permanecer em equilíbrio. Eles mudam quando percebem informação seletiva, em forma de novidades, em seus ambientes. Diferente da seleção biológica, nas escolhas humanas o ambiente natural dá lugar a um ambiente virtual que deve ser considerado uma criação interna do próprio sistema em desenvolvimento. Ele próprio exibe variações permanentes para si próprio. A relação social sistema/ambiente é considerada consequentemente como uma relação entre sistemas de comunicação, e não uma relação entre cultura e ação individual.

Ao tentar compreender, uma cadeia flutuante de significados entra em funcionamento. Surge um sentido de delimitação da rede de web ou de tv, como sucessão não-linear de significados. Isso rompe definitivamente os limites das diversas formas de "prisão" mediática. Amarrado ao linear, à reprodução incessante de ruído, de repetição , de prolixidade, de redundâncias de conteúdos, apenas a mudança de formatos, ela só, não consegue disfarçar o desejo por mais, de ir além de cada horizonte dado em cada um dos instantes subsequentes. A natureza fluida do Lebenswelt (mundo de vida) estético, enquanto vivência, exige por sua vez leituras fluidas, sem amarração a hierarquias. É com o advento da Internet que se revela definitivamente que a leitura é não-linear, que novas mídias exigem novas leituras e novas linguagens, como por exemplo a linguagem da cibermidia.

A complexidade estética surge de uma diferenciação nítida entre comunicação e cognição. O aspecto cognitivo da experiência humana, seu pensamento e suas percepções, faz parte unicamente da sua vida psíquica. Mas quando um sinal for exibido, trata-se já de comunicação e não mais de experiência pessoal. Ela precisa ressurgir em forma de linguagem audível e em forma de gestos e sinais visíveis. Só depois desta transformação de elemento psíquico para elemento comunicativo a experiência pessoal pode ser processada pelo sistema social. Este lhe pode atribuir um significado bem diferente do intencionado pelo sistema psíquico, tal qual um corpo biológico, para usar outra metáfora, funcionaliza as suas células, usando-as tanto para constituir a pele como para formar o cérebro. O sistema de comunicação usa as ações comunicativas dos 
participantes para criar o seu próprio sistema. Ele as usa, abusa, esgota as contribuições dos participantes na sua própria dinâmica de processar informações.

Comunicação não é, portanto, apenas uma forma de interação atribuída a uma ação individual, mas uma forma de surgimento, diferenciação e autorenovação de sistemas sociais. "Apenas a comunicação sabe comunicar", como o formula Luhmann.

Sistemas de comunicação sempre operam num ambiente complexo, sujeito à subjetividade estética. Eles recorrem a contextos comunicativos autopoiéticos, que estabelecem os seus próprios limites e formam um todo social altamente diferenciado, complexo (no sentido de inesgotável nas suas combinações). Como diz Levy, estabelecendo uma relação entre cognição e comunicação: "O regime de produção e distribuição do saber depende não apenas das especificidades do sistema cognitivo humano, mas também dos modos de organização coletiva e dos instrumentos de comunicação e tratamento da informação."3

Isso nos leva a crer que o grau de funcionalidade do processo de comunicação encontra seus limites não apenas nas faculdades limitadas dos participantes (de perceberem, pensarem e se expressarem), ou seja nos elementos que estes fornecem, mas também nos limites das experiências estéticas que os sistemas de comunicação adotam para si próprios.

\section{O caminho da linguagem da mídia}

Media, plural de medium. Meio, intermediador. Emendam rupturas entre os observadores e os mundos que a cada um constrói para si. Eles fazem da ruptura uma costura e constróem pontes, permitindo assim acoplamentos de estruturas de comunicação. Através do uso de media, observadores tentam influir em outros, ao mesmo tempo de que são influenciados pelo ambiente, operado por media, sendo a linguagem o meio principal.

A dificuldade está no fato de que linguagens são produtos simbólicos, e enquanto tais são resultado de ação humana. Bourdieu (2000) faz desta ação o

${ }^{3}$ Levy, 1996, p. 171 
fundamento das relações sociais do cotidiano, diferenciando três vertentes do debate dos sistemas (meios, ambientes) simbólicos: linguagem como instrumento do conhecimento como meio de comunicação como instrumentos de dominação.

Podemos ver por detrás desta concepção as áreas onde as vertentes se aplicam: à ciência, à mídia, à política, lato senso.

Qualquer que seja o âmbito de sua intervenção, a linguagem aparece como uma estética mediatizada, uma estética que é ela mesma o significado da operação de media que operam com sinais que, por si não "possuem" significado. Sinais e símbolos são ativados pelos contextos (ambientes, meios, media) aos quais se expõem, O contexto le plus elevé é a linguagem, que consegue se constituir em sistema autopoiético por excelência, onde cada elemento do dicionário (por exemplo palavra) se explica por outros elementos, outras palavras, de forma circular.

Quando o próprio código é flexível e sujeito a redefinições, como é o caso da linguagem, então o "criador" já está construído socialmente. Em outras palavras: pessoas podem discordar, mas são capazes de se compreender mutuamente usando codificações de superior ordem, ou seja, media e sistemas de comunicação.

Sinais capacitam sistemas a se expressar. Media possibilitam, assim, usar sinais que denominam fenômenos no mundo, já que no mundo construído por comunicação não há outras coisas além de sinais.4 E os sinais são pura produção de um sistema.

Linguagem é o medium predileto para compreender o mundo. Mas as palavras não são as coisas. O medium "linguagem" coloca a disposição sinais acústicos e óticos a fim de descrever o mundo. Ele aumenta as possibilidades de uma comunicação mais refinada. Sinais e linguagem estão geralmente embutidos em de "media simbolicamente generalizados", onde eles são equipados com sentido. Luhmann localiza quatro media principais, simbolicamente generalizados: Verdade, poder, dinheiro, amor.

\footnotetext{
${ }^{4} \mathrm{Ou}$, se as houver, elas serão compreensíveis apenas através de sinais
} 
Estas e outras "áreas de sentido"5 em destaque funcionam como redutores da improbabilidade da aceitação de uma oferta de comunicação. Eles estimulam a aceitação de sentido em contextos sociais como política, economia, relações familiares e íntimas, produção científica. Em princípio, qualquer tema destacado em comunicação pode funcionar como medium simbolicamente generalizado. Eles acoplam motivação individual com seleções altamente criteriosos do sistema de comunicação.

O medium "poder", por exemplo, assegura com certa probabilidade a motivação do "dominado" para prestar serviços, mesmo desagradáveis, via de regra em forma de "trabalho".

O medium "amor" eleva a probabilidade dos parceiros aceitaram seus pontos de vista, mesmo que sejam bastante diferentes.

O medium "dinheiro" assegura o acesso de pouco risco à propriedade alheia.

O medium "verdade" garante a fé em conhecimentos que não são mais percebíveis pelo aparelho sensor humano normal. Complexidade é reduzida.

O medium "opinião pública" é, na verdade, um hipermedium, já que ele contêm todos os media simbólicos, ao qual a imprensa e mídia audiovisual dão forma. Mas o medium é a própria opinião pública. Os meios de difusão técnica como livros, rádio, televisão, telefone, Internet, suportam os media simbolicamente generalizados e os reforçam. Mas o simbolismo pertence ao medium e a informação há de ser codificada para sua transmissão técnica.

A escrita, a imprensa, a rádio e a transmissão electrónica de dados marcam o surgimento de "meios técnicos de difusão" que ultrapassam as possibilidades de comunicação além dos limites das relações face-a-face. Eles separam a comunicação da presença física imediata, propiciando ganhos de independência espacial e temporal.

Sua evolução (dos sinais de fumaça até a comunicação via satélite) é marcada pela ampliação do alcance de seres geograficamente e historicamente distantes. Nesta evolução nem tudo sobreviveu. Começaram a desaparecer algumas possibilidades de controle social possíveis comparados com a comunicação entre seres fisicamente presentes e/ou ao alcance. Além disso,

\footnotetext{
5 A nível da comunicação eles aparecem como "temas especiais" que "atraem" e "orientam" a comunicação
} 
não estão sobrevivendo as formas normativas ("tabus") que limitaram o espectro daquilo que poderá tornar-se tema da comunicação.

O universo do comunicável é infinitamente expansível, tal como a combinação mútua de todos os átomos do universo entre si seria uma tarefa infindável. Os meios técnicos delimitam, no entanto, tal universo, por razões ligadas ao grau de desenvolvimento tecnológico. Meios de difusão eram, por muito tempo, pouco interativos, atuando via de regra numa única direção. Apenas com o advento da Internet e de sua difusão massiva, os limites técnicos se expandiram exponencialmente.

A complexidade comunicativa, possibilitada pela linguagem, é acoplada a sempre novos meios técnicos. As interações diretas diminuem, e as mediatizadas aumentam proporcionalmente. Subsequentemente o controle diminui e a autonomia dos participantes comunicandos ganha mais um grau de liberdade. A consequência da comunicação tecnicamente mediatizada é a individualização da pessoa, cuja identidade passa a se constituir como produto de diferenciações e comparações, e não mais como produto de identificação. Meios de difusão elevam tanto a comunicabilidade (para fora) como a incomunicabilidade (para dentro).

\section{O caminho da comunicação como interpretação}

Tentamos traçar aqui algumas hipóteses sobre possíveis aspectos do desenvolvimento futuro, que refletem a visão pessoal do autor.

Na concepção tradicional, a comunicação atribuiu sentido e significado a fatos, sejam eles físicos ou sociais ou de outra natureza. A concepção sistêmica mostra que o fato já é uma interpretação, e se trata, portanto da atribuição de sentido a interpretações. Trata-se de relações circulares, de um jogo que não tem fim e em cujo começo está a incerteza. Descobrir, inventar, ou fazer arte passam a ter sua raiz na mesma atividade, na interpretação. De repente se abre um espaço que virtualmente não tem delimitação. Um novo tipo de espaço, portanto, difícil de ser manuseado por nossa imaginação, que está condicionada a uma visão linear, de sistemas fechados, limitados. 
O novo deste espaço, denominado de cultura, de virtual, de imaginário, é que nele não há formas que possam ser completas, absolutas, finais, mesmo que fossem enclausurados no museu mais tradicional. Mesmo que o corpo interno do significado não mude, o seu corpo externo, seu entorno, seu ambiente, suas formas de mediatização se transformam a cada instante.

Desse modo, todas as formas dominantes de interpretação , todas as escolas, técnicas, abordagens imagens, não fazem mais do que confirmar a eterna instabilidade na diferenciação incessante da atividade de interpretar. Ela aparece como um movimento infinito, como um interminável jogo de diferenciação e renovação, produzindo uma obra que não se pode concluir, uma obra que, em sua eterna criação, nunca encontra seu fim. Mais que isso, a própria atividade de finalizar uma obra passa a constituir a essência da arte de sua criação. A dificuldade e o segredo está em saber parar no momento certo, após ter iniciado.

Ao se atrever na aventura da interpretação artística e de sua apreciação crítica, no campos social (que é o caso do nosso mestrado), não podemos partir de uma interpretação qualquer, a priori, se se encontra aquilo que se esconde atrás do visível, ou das aparências, ou não é uma questão da procura por u ma suposta coisa-em-si. Será que há um verdadeiro rosto atrás das máscaras?

É nossa experiência ou vivência social, nossa Lebenswelt imediata, quem interpreta, quem se apropria do que está sendo interpretado. E é por isso que a própria experiência passa a ser fator de infinita multiplicação. Não apenas nas cabeças de uns futuristas, não no caráter múltiplo real que se experimenta hoje, na nossa própria vida múltipla. Estamos expostos ao mundo dos sentidos, dos significados, que, por isso mesmo, sempre poderão tornar-se outros sentidos. A interpretação é tanto um fenômeno psíquico como social. Num artigo programático, Callon (et al., 1985) sugeriu que distinções tais como interno contra externo, ou psíquico (cognitivo) contra social, devem ser superadas usando a noção de interpretação (translation). Ambos os tipos de sistemas usam sistemas de interpretação mútua para se acoplarem, já que o observado não pode ser processado tal qual se encontra. Os dados têm que ser traduzidos na "linguagem" de cada um dos sistemas participantes: em sons, imagens, letras, palavras, gestos e etc., e estes em impulsos elétricos, se o sistema tradutor for de ordem técnica. 
Interpretação (ou tradução, quando falamos de línguas) engloba todos os mecanismos e estratégias através de que um ator identifica outras ações (elementos) e as coloca com relação umas com as outras. Cada ator constrói um universo em torno dele, uma rede em mudança, de elementos variados, que ele tenta interligar e fazer depender dele.

Os sistemas da interpretação revelam facilmente os seus problemas quando se usa o exemplo da tradução de línguas estrangeiras. A mesma palavra pode ter significados diferentes em idiomas diferentes; várias traduções são às vezes possíveis. Assim, um sistema de interpretação pode ser compreendido como um sistema em que os intérpretes se comunicam continuamente entre eles sobre as traduções possíveis. Os intérpretes de usuários nativos estabelecem suas disputas usando dicionários, mas num sistema de tradução a disputa entre perspectivas diferentes é uma constante. Isso vale sobretudo para o sistema ciência.

Quaisquer comunicações que ocorrem via interfaces podem ser consideradas como interpretações de sinais alheios. Quando o significado da interpretação muda, ela transporta um código diferente, uma construção de uma série de construções nas interfaces entre sistemas. A interpretação já não é atribuída a um centro de comando, ou a uma cultura central, mas se refere a supersistema emergente. Os vários ciclos passam a funcionar em rede, que constitui um sistema de interpretação de segunda ordem, ou seja se torna referência para os demais.

A rede, a web, nos ensina que a instância interpretadora, isto é, o centro de controle, não pode mais ser observado diretamente desde que está distribuído nas comunicações. Além disso, as seleções podem ocorrer em sentidos diferentes, e assim a vários ciclos, antes desintegrados, soltos, podem coexistir. Cada sistema participante pode perceber-se instância integradora, desde que os critérios para a integração são diferentes entre sistemas, e os horizontes do tempo podem ser diferentes também.

Surge uma nova forma de diferenciação funcional, baseado na interpretação de segunda ordem referenciada pela rede comum. A emersão desta nova forma de regime social depende do grau de diferenciação alcançado pelo sistema. 
Trata-se de um evolutionary turn, onde sistemas de comunicação e interpretação co-evoluem porque interagem em co-variação. Quando um padrão de co-variação é mantido pelo tempo, os sistemas podem começar a coevoluir. Dão forma um ao outro. Sucedem, fazem época, ou simplesmente se contentam em aparecer em círculos pequenos. Até que cheguem a compreender, entre outras coisas, como a informação nova pode entrar num sistema, vindo de um ambiente que co-evolui com os sistemas de comunicação contemporâneos.

\section{Caminhos do mestrado em comunicação e linguagens da UTP}

O programa focaliza a área de concentração "interfaces de linguagens verbais e não-verbais". O esforço consiste em explorar as potencialidades das mídias e suas interfaces, assim como a grande variedade de abordagens e práticas comunicativas existentes. Isso parece apenas possível, se se permitir a sua coevolução, por sua vez dependendo das interfaces comunicativas.

Estuda-se a interface entre diversas formas de mídias (da fotografia ao filme) e outros códigos em sintonia criadora, sob novas tecnologias ou não, suas condições de produção, recepção e circulação. Isso implica na análise e crítica a partir de diferentes teorias interpretativas das diversas estéticas comunicacionais, para compreender seu papel e seus valores para a sociedade. À medida do avanço tecnológico recortes se centram cada vez mais nos processos promovidos pela interatividade, na relação homem-máquina, mediada por interfaces técnicas. Isso eleva o papel da máquina a um fator decisivo, ou mesmo a um agente de instauração estética próprio.

A interatividade, como intermediário essencial, ativo, exerce um papel transformador. Ela faz com que haja compatibilidade, igual ao uso de códigos comuns que criam sinergia, entre homem e máquina 6

\footnotetext{
6 “A interatividade como relação recíproca entre usuários e interfaces computacionais inteligentes, suscitada pelo artista, permite uma comunicação criadora fundada nos princípios da sinergia, colaboração construtiva, crítica e inovadora." (Plaza, 2000)
} 
No nosso caso ainda nos deparamos com novas linhas de pesquisa, que levam em conta a natureza substancial da informação ordenada por várias formas, formatos, linguagens, substâncias.

A linha “Análise de linguagens midiáticas" tem como domínio o estudo de textos midiáticos verbais e não verbais, procedimentos narrativos e mecanismos de articulação de sentido em contextos socioculturais. A outra linha "Cibermídia e meios digitais" está voltada para o estudo da comunicação em rede, dos processos e produtos hiper e multimidiáticos, assim como do impacto dos meios digitais com suas respectivas interfaces.

Os conteúdos interagem em termos de co-variações apenas quando há "janelas de comunicação", recíprocas. Ou seja, quando cada comunicação provoca variação em todos os sistemas participantes. Cada sistema de comunicação (linhas, abordagens, grupos, temas) pode co-variar com vários outros sistemas de comunicação; cada co-variação adiciona um outro grau de liberdade à comunicação dentro dos sistemas respectivos.

Uma co-variação, entretanto, é parte da variação total dos sistemas conectados, cujo resultado é uma resultante. Através dela, usando-a como referência, os co-sistemas informam-se mutuamente. A informação mútua ou o co-variação podem ser usados como uma medida da comunicação.

Aplicando um ponto de vista evolucionista, seria de se esperar que apenas as variantes mais "fortes" sobreviverão enquanto fenômenos específicos. Mas, olhando do ponto de vista de uma teoria da co-evolução, da co-construção, podemos observar que são muitas as formas e formatos que ao longo do tempo caminham para estabilização mútua, cada uma em seu ciclos de co-evolução específica.

Desta forma, as diferentes linguagens não concorrem num jogo de soma zero, mas sua diferenciação leva a uma "riqueza maior", a um tipo de cultura multi e plurifuncional, com limites muito amplos de interpretação.

Sabemos da teoria sociológica, que o processo de co-evolução de linhas de pesquisas e abordagens teóricas requer que os sistemas participantes apresentem uma certa interdependência mútua, da maneira que a variação e mudança de ações de uma parte dependa das irritações e dos estímulos mútuos. 


\section{Referências}

Barthes, Roland (1990). O óbvio e o obtuso, Rio de Janeiro.

Bateson, Gregory (1972) Steps to an Ecology of Mind, San Francisco.

Bourdieu, Pierre (2000), O poder simbólico. 3a.ed., Rio de Janeiro.

Callon, M. (1985), Some elements of a sociology of translation. In: Journal of Law, pp. 196-233

Levy, Pierre (1996), A inteligencia coletiva - por uma antropologia do cieberespaço, S. Paulo.

Luhmann (1987) O amor como paixão - para a codificação da intimidade, Lisboa.

McLuhan (1964), Os meios de comunicação como extensões do homem. Rio de Janeiro.

Plaza, Julio (2000), Arte e Interatividade: Autor-Obra-Recepção, in www.plural.com.br/jplaza/textoo1.htm(10/2004)

Stockinger, Gottfried (2003), A sociedade da comunicação - o contributo de Niklas Luhmann, Rio.

Watzlawick, Paul, et.al. (1967), A pragmática da comunicação humana, São Paulo. 